\title{
A epistemologia de Johannes Hessen e a gnosio- logia de Paulo Freire
}

\author{
Sabrina Gabriela Klein \\ Cristiane Muenchen \\ Universidade Federal de Santa Maria (Brasil)
}

\section{Resumo}

Este trabalho tem a pretensão de apresentar uma construção de um embasamento teórico-epistemológico fundamentado na relação entre a epistemologia de Johannes Hessen e a gnosiologia de Paulo Freire, na perspectiva da Abordagem Temática. O objetivo da análise é apresentar elementos teóricos para compreender o processo de apreensão de temas nessa perspectiva e, dessa forma, contribuir com as elaborações de práticas pedagógicas. A epistemologia de Hessen fornece elementos para compreender o processo de interação entre sujeito e objeto. A gnosiologia de Freire permite uma ampliação do olhar pedagógico sobre o processo didático, necessária para que a apreensão ocorra. As análises permitem inferir que o processo de apreensão de temas ocorre por meio da interação entre professores, estudantes, cientistas (sujeitos do conhecimento) com o tema (objeto do conhecimento) proveniente da realidade. A interação entre sujeitos e objetos ocorre através de processos didático-pedagógicos interdisciplinares, dialógicos e problematizadores, que devem garantir a apreensão do significado e a interpretação dos temas por parte dos alunos.

Palavras-chave: Abordagem temática. Hessen. Freire. Ensino de ciências.

\section{Johannes Hessen's epistemology and Paulo Freire's gnosiology}

\section{Abstract}

This paper intends to present the construction of a theoretical-epistemological foundation based on the relationship between Johannes Hessen's epistemology and Paulo Freire's gnosiology, from the perspective of the Thematic Approach. The objective of the analysis is to present theoretical elements to understand the process of apprehension of themes in this perspective and, thus, contribute to the elaboration of pedagogical practices. Hessen's epistemology provides elements to understand the process of interaction between subject and object. Freire's gnosiology allows a broadening of the pedagogical view of the didactic process, necessary for the apprehension to occur. The analyses allow us to infer that the process of theme apprehension occurs through the interaction between teachers, students, scientists (subjects of knowledge) with the theme (object of knowledge) coming from reality. The interaction between subjects and objects occurs through didactic-pedagogical interdisciplinary, dialogical and problematizing processes, which should guarantee the apprehension of meaning and interpretation of the themes by the students.

Keywords: Thematic approach. Hesse. Freire. Science teaching. 
A epistemologia de Johannes Hessen e a gnosiologia de Paulo Freire

\section{Epistemología de Hessen y gnoseología de Freire: una mirada al enfoque temático}

\section{Resumen}

Este trabajo presenta una construcción teórico-epistemológica, basada en la epistemología de Hessen y la gnoseología de Freire, en el contexto de una mirada a la perspectiva curricular del Enfoque Temático. El objetivo del análisis es proporcionar una base teórica para comprender el proceso de aprehensión de los temas en esta perspectiva y, así, contribuir a la elaboración de prácticas pedagógicas. La epistemología de Hessen proporciona elementos para comprender el proceso de interacción entre sujeto y objeto. La gnoseología de Freire permite ampliar la mirada pedagógica del proceso didáctico, necesaria para que se produzca la aprehensión. Los análisis permiten inferir que el proceso de aprehensión de temas se da a través de la interacción entre profesores, estudiantes, científicos (sujetos de conocimiento) con el tema (objeto de conocimiento) proveniente de la realidad. La interacción entre sujetos y objetos se da a través de procesos didáctico-pedagógicos interdisciplinarios, dialógicos y problemáticos que deben garantizar la comprensión por parte del alumno del significado e interpretación de los temas.

Palabras clave: Enfoque temático. Hessen. Freire. Enseñanza de las ciencias.

\section{Introdução}

desenvolvimento de pesquisas científicas na área da educação está constantemente buscando por mais qualidade de ensino. $O$ currículo torna-se, nesse sentido, um campo importante de análise. Na área do Ensino de Ciências, a utilização de temas tem sido apresentada como possibilidade para a superação de currículos únicos e fechados (DELIZOICOV; ANGOTT; PERNAMBUCO, 2007; HALMENSCHLAGER, 2014). Contudo, existem diferentes propostas pedagógicas baseadas em temas.

Halmenschlager (2014) investigou como vem ocorrendo a inserção de temas nos componentes curriculares da área das ciências da natureza e coloca que iniciativas temáticas apresentam aspectos comuns, complementares e até mesmo divergentes. Entre essas propostas, encontra-se a Abordagem Temática (AT), uma perspectiva ampla e crítica, preocupada com uma educação dialógica e problematizadora, com vistas à reestruturação de currículos.

No livro "Ensino de Ciências: Fundamentos e Métodos", os autores Delizoicov, Angotti e Pernambuco (2007) sinalizam que a AT consiste na articulação de temas e conceitos científicos na programação e no planejamento curricular, sendo os temas, não os conceitos, o ponto de partida do programa 
curricular. Os conceitos a serem estudados deverão ser escolhidos de forma a dar conta da apreensão do tema. Entretanto, como isso acontece?

Assim, este estudo é um recorte de uma pesquisa mais ampla, ao nível de doutoramento, em que se busca compreender como ocorre o processo de apreensão temática. Neste trabalho, tem-se a pretensão de apresentar a construção de um embasamento teórico-epistemológico fundamentado na relação entre o teólogo e filósofo alemão Johannes Hessen (1889-1971) e o educador brasileiro Paulo Freire (1921-1997).

Essa relação será construída pelo olhar da concepção epistemológica sobre a teoria do conhecimento de Hessen e o viés gnosiológico da teoria educacional de Freire. A intenção dessa relação é apresentar elementos que possam contribuir teoricamente para explicar como ocorre o processo de apreensão de temas na perspectiva curricular da AT e, dessa forma, contribuir com a elaboração de práticas pedagógicas em AT que sejam coerentes com seus pressupostos e criem condições para que os temas sejam apreendidos pelos estudantes.

Delizoicov (1991) relata que, através da necessidade de desenvolver conhecimentos contextualizados e que de fato auxiliassem os educandos no entendimento crítico dos fenômenos e situações por eles vividos, realizou a leitura e a interpretação da concepção freireana para o contexto escolar. Delizoicov é um dos autores do livro "Ensino de Ciências: fundamentos e métodos" (DELIZOICOV; ANGOTTI; PERNAMBUCO, 2007), em que a AT é apresentada com elementos da concepção de Freire. Nas palavras dos autores,

A prática e a reflexão de uma educação progressista cuja opção seja a estruturação curricular na perspectiva da abordagem temática - como é a que vem sendo trabalhada neste livro e contemporaneamente tem sido proposta - remetem às contribuições pioneiras de Freire e Snyders (DELIZOICOV; ANGOTTI; PERNAMBUCO, 2007, p. 270).

Dessa forma, justifica-se a importância do olhar gnosiológico de Freire nesta análise. Em sua tese, Delizoicov (1991, p. 4) utiliza parâmetros epistemológicos fornecidos por Kuhn e Piaget, admitindo que ambos têm em comum a ideia freireana que "[...] o conhecimento se origina na interação sujeito-objeto, na não neutralidade do sujeito nem do objeto, e na não-linearidade na construção desse conhecimento". Com base nessa proposição de interação não 
A epistemologia de Johannes Hessen e a gnosiologia de Paulo Freire

neutra e não-linear entre sujeito-objeto, da qual o conhecimento se origina, que se buscou aprofundar nesse estudo. Por isso, também, a importância do olhar epistemológico de Hessen, visto que o autor constrói sua teoria do conhecimento com base nas relações entre sujeito e objeto.

\section{A epistemologia de Hessen e gnosiologia de Freire}

Hessen (2012, p. 19) caracteriza a teoria do conhecimento como "[...] uma interpretação e uma explicação filosófica do conhecimento humano". $\bigcirc$ autor descreve o fenômeno do conhecimento através do método fenomenológico, ou seja, por meio da essência geral, [...] aquilo que é essencial a todo conhecimento, aquilo em que consiste sua estrutura geral" (HESSEN, 2012, p. 19).

As características gerais do conhecimento ao que o autor se refere são as relações entre sujeito e objeto. De acordo com o autor, a relação entre sujeito e objeto é dualística, mas, ao mesmo tempo, recíproca. Dualista, já que, nessa relação, ambos permanecem sempre separados, ou seja, ser sujeito é completamente diferente de ser objeto. Recíproca, porque "[...] o sujeito só é sujeito para um objeto e o objeto só é objeto para um sujeito [...] A função do sujeito é apreender o objeto; a função do objeto é ser apreensível e ser apreendido pelo sujeito" (HESSEN, 2012, p. 20).

autor acrescenta nessa relação mais um elemento, a "imagem". Ele explica que a "imagem" surge para o sujeito através da sua relação com o objeto, pois, ao apreender o objeto, o sujeito sai da sua esfera própria e apreende determinações da esfera do objeto, entretanto, o objeto "[...] não é arrastado para a esfera do sujeito, mas permanece transcendente a ele" (HESSEN, 2012, p. 20). Com isso, surge no sujeito uma "imagem" do objeto. Nessa relação, o objeto é determinante, o sujeito determinado e a imagem "[...] é o meio com o qual a consciência cognoscente apreende seu objeto" (HESSEN, 2012, p. 21).

Dessa forma, o conhecimento passa a ser caracterizado por três elementos principais: sujeito, imagem e objeto. Retomando a ideia de que sujeito e objeto possuem características próprias (ontológicas), é importante destacar que o objeto só se mantém nessa relação na medida em que é objeto do conhecimento. No momento em que o objeto cessa essa relação, o sujeito apenas 
deixa de ser sujeito cognoscente. "Daí a distinção entre sujeito e sujeito do conhecimento e entre objeto e objeto do conhecimento e, ao mesmo tempo, a sua correlação recíproca no processo do conhecimento" (BRICK, 2017, p. 51).

Conforme expresso por Sangiogo (2014), Hessen refere-se a um conhecimento de modo geral, não restrito apenas ao conhecimento científico e, dessa forma, ganha relevância e ajuda a entender especificidades do conhecimento científico e sua disseminação para outros grupos sociais, além do científico. Neste caso, será utilizada a sua concepção sobre a teoria do conhecimento para analisar a perspectiva da AT.

A visão epistemológica de Hessen é utilizada por Brick (2017) em uma análise de práticas educativas, tendo como referência a realidade. $\bigcirc$ autor pressupõe que o objeto de Ensino de Ciências naturais é a realidade e busca desenvolver "[...] uma concepção de realidade que fomente práticas educativas ético-críticas, que reconheça que objetos de conhecimento em situações de ensino podem sintetizar múltiplas dimensões constituintes da realidade" (BRICK, 2017, p. 11).

Brick (2017) caracteriza a situação de ensino através de uma interpretação gnosiológica. Compreende o momento de ensino/aprendizagem como uma situação gnosiológica e que a relação entre a teoria do conhecimento e o ensino não existe sem ter o conhecimento como objeto de ensino/ aprendizagem.

autor discute quais são os elementos constituintes de uma situação de ensino, deixando claro que não pretende propor um modelo em virtude da diversidade de possibilidades de funções sociais para a escola. Dessa forma, considera, de modo geral, que a situação de ensino aconteça entre professor, aluno e "conteúdo" a ser aprendido.

Logo, professor e aluno são os sujeitos dos conhecimentos essenciais do ato educativo, pois sem eles não existe situação de ensino. Mas, também, é possível considerar outras diversas possibilidades de sujeitos envolvidos direta ou indiretamente, como, por exemplo: pais ou outros familiares, demais professores, demais alunos, demais profissionais da escola, membros da comunidade local, entre outros. Além dos exemplos citados, há, ainda, sujeitos históricos produtores de conhecimento reconhecido e legitimado, que merecem ser considerados, os cientistas. Esses, participam da situação de 
A epistemologia de Johannes Hessen e a gnosiologia de Paulo Freire

ensino enquanto estiverem vinculados pelo professor, pelo aluno ou ambos ao conhecimento por eles produzido (BRICK, 2017).

Assim, considera-se de maior participação da situação de ensino: o Professor (P) no papel de professor, no planejamento ou concretização de uma situação de ensino; o Aluno (A); e os Cientistas (Sc) de participação fundamental, embora não necessariamente de atuação síncrona e direta (BRICK, 2017 ).

Outro elemento importante da relação é a identificação do objeto do conhecimento. Anteriormente, mencionou-se que a situação de ensino acontece entre professor, aluno e "conteúdo" a ser aprendido. Logo, o objeto do conhecimento que está sendo considerado é o "conteúdo" ou a "matéria". Tal "matéria" (M) é resultado do processo de transposição didática do conhecimento científico produzido pelos cientistas (BRICK, 2017).

$\bigcirc$ autor pontua que se deve levar em conta que estudantes e professores mobilizam diferentes tipos de conhecimentos em uma situação de ensino. Para os alunos, as chamadas concepções alternativas e, ainda, de forma mais ampla, os conhecimentos de senso comum. Para os professores, pode-se considerar os conhecimentos de senso comum pedagógico e, também, os conhecimentos de senso comum relativo à atividade científica.

Contudo, o que se pretende é articular as discussões realizadas até o momento com o olhar gnosiológico de Freire. A teoria do conhecimento de Freire é gnosiológica, uma vez que é "[...] mais ampla, abrangente e, por isso mesmo, menos específica enquanto análise do conhecimento científico" (DELIZOICOV, 1991, p. 4).

Delizoicov (1991), em sua tese, defende uma educação progressista, em que a formação do educando visa sua atuação na sociedade, na perspectiva de suas transformações, tendo como premissa a concepção problematizadora e dialógica proposta por Paulo Freire, com vistas à superação da "consciência ingênua pela "consciência crítica". Dessa forma, explora-se, aqui, um pouco mais a concepção freireana de educação, tomando como base, principalmente, a obra Pedagogia do Oprimido:

Aquela que tem de ser forjada com ele e não para ele, enquanto homens ou povos, na luta incessante de recuperação de sua humanidade. Pedagogia que faça da opressão e de suas causas objeto de reflexão dos oprimidos, de que resultará o seu engajamento 
necessário na luta por sua libertação, em que esta pedagogia se fará e refará (FREIRE, 2018, p. 43, grifo do autor).

Tal obra "[...] permanece atual e relevante, ainda mais nesses tempos em que 'voltamos a viver como cinquenta anos atrás'" ISOUZA; MEDONÇA, 2018 , p. 2). Sobre essa ideia, os autores estão referindo-se aos tempos difíceis de movimentos da Escola sem Partido e outros "avanços" do conservadorismo.

Assim, defende-se o caráter pedagógico da revolução "[...] como processo, permanente, de aprendizado em que lideranças revolucionárias e povo oprimido, juntos, dão fim à sociedade opressora e repressora, instaurando uma outra ordem social sob a égide de um novo tipo de humanismo" (SOUZA; MEDONÇA, 2018 , p. 4). Através de uma ação libertadora de reflexão e ação, busca-se transformar a dependência do oprimido, aquele que, na contradição em que vive, tende a ser também opressor, em independência. Para isso, é necessário reconhecer-se oprimido, engajar-se e entregar-se à práxis libertadora e inserir-se criticamente na realidade opressora, atuando sobre ela (FREIRE, $2018)$.

Freire argumenta que o caminho para esse trabalho de libertação não é o ato de "depositar" a crença da liberdade, mas o de dialogar em busca da sua conscientização. Nesse viés, a prática pedagógica é uma prática humanizadora, em que educador e educando "[...] cointencionados à realidade, se encontram numa tarefa em que ambos são sujeitos no ato, não só de desvelála e, assim, criticamente conhecê-la, mas também no de recriar estes conhecimentos" (FREIRE, 2018, p. 78).

A concepção de educação de Freire é problematizadora, libertadora e oposta à educação por ele denominada de bancária. Na concepção bancária, o educador é o sujeito do processo e os educandos são os objetos, negando-se a ontológica vocação de ser mais. Ao contrário, na concepção libertadora e problematizadora, tem-se um ato cognoscente, e uma situação gnosiológica "[...] em que o objeto cognoscível, em lugar de ser o término do ato cognoscente de um sujeito, é o mediatizador de sujeitos cognoscentes" (FREIRE, 2018, p. 94). Assim, supera-se a contradição educador-educando, e a relação dialógica estabelecida se torna indispensável à cognoscibilidade dos sujeitos cognoscentes em torno do mesmo objeto cognoscível. Sendo assim, a educação problematizadora é uma situação gnosiológica que se sustenta na dialogicidade. 
A epistemologia de Johannes Hessen e a gnosiologia de Paulo Freire

O educador problematizador, investigador crítico, é sempre um sujeito cognoscente, seja ao preparar-se para sua aula ou no encontro dialógico com os educandos. Dessa forma, o educador refaz, constantemente, seu ato cognoscente na cognoscitividade dos educandos, os quais são, também, investigadores críticos. Freire coloca que

Pelo fato mesmo de esta prática educativa constituir-se em uma situação gnosiológica, o papel do educador problematizador é proporcionar, com os educandos, as condições em que se dê a superação do conhecimento no nível da doxa pelo verdadeiro conhecimento, o que se dá no nível do logos (FREIRE, 2018, p. 97).

A educação problematizadora parte do caráter histórico dos homens, reconhecendo-os como seres inacabados. Parte, também, das relações homens-mundo, propondo aos homens sua situação como problema, como situação de seu ato cognoscente, para superação da percepção ingênua que dela tenham, para que sejam capazes de transformá-la (FREIRE, 2018). Nesse sentido, percebe-se a categoria de criticismo de Hessen, citada anteriormente, 8 ao considerar a ideologia de Freire sobre o inacabamento dos seres humanos.

O diálogo, elemento fundamental, sem o qual não se faz a educação problematizadora, deve ser baseado nas dimensões da ação e da reflexão - práxis - de forma a não ser apenas verbalismo, blá-blá-blá ou ativismo. $\bigcirc$ diálogo pressupõe amor, humildade, fé nos homens, esperança e pensamento crítico. "Somente o diálogo, que implica um pensar crítico, é capaz, também, de gerá-lo. Sem ele não há comunicação e sem esta não há verdadeira educação" (FREIRE, 2018, p. 115).

Ana Saul e Alexandre Saul (2018), ao realizarem uma reflexão teórica sobre currículo, baseados na obra Pedagogia do Oprimido, argumentam que Freire possui o diálogo como pressuposto ético-político-gnosiológico. Os autores constroem uma trama conceitual Freireana (Figura 1), para subsidiar discussões e práticas curriculares. A trama se dá por meio do entrelaçamento das categorias: reflexão crítica sobre a prática, linguagem, diálogo, participação e transformação. 

A epistemologia de Johannes Hessen e a gnosiologia de Paulo Freire

programas escolares estruturados didático-pedagogicamente, para que, através deles, o educando se aproprie do conhecimento subjacente.

Dessa forma, em sala de aula, deve-se propiciar o diálogo entre os conhecimentos dos alunos e dos professores em torno dos fenômenos e/ou situações previamente selecionadas para discussão, ou seja, um fenômeno e/ ou situações codificadas serão descodificados em processo coordenado pelo professor, via diálogo e problematização. Desse modo, o professor tem a função de problematizar as interpretações dos educandos, procurando limitações. Delizoicov afirma que

A finalidade é promover o distanciamento crítico do aluno do seu conhecimento prevalente e enfim formular problemas que os alunos não formulam e, problematizadoramente, ao longo do processo educativo, desenvolver as soluções que o conhecimento científico a eles tem dado" (DELIZOICOV, 1991, p. 179).

Os fenômenos e/ ou situações da codificação inicial são obtidos com a investigação temática realizada anteriormente à atividade educativa de sala de aula. Os conhecimentos sobre os fenômenos e/ou situações que a comuni-

10 dade e os alunos já possuem começam a ser apreendidos pela equipe também durante a investigação temática. Os conhecimentos científicos com o qual o fenômeno e/ou situação podem ser interpretados pertencem ao domínio do professor, o qual seleciona os conhecimentos escolares científicos a serem vinculados. Definidos os conteúdos escolares, estes deverão ser desenvolvidos nas atividades educativas e o modelo didático-pedagógico é, então, empregado na sala de aula (DELIZOICOV, 1991).

Assim, apresentam-se os principais conceitos de Hessen e sua extensão ao contexto educativo realizado por Brick e, ainda, os principais conceitos gnosiológicos de Freire. Com base nas discussões teóricas estabelecidas, no próximo tópico analisa-se a perspectiva da AT.

\section{A perspectiva da Abordagem Temática em análise}

Inicialmente detalham-se mais alguns elementos colocados pelos autores Delizoicov, Angotti e Pernambuco (2007) no livro "Ensino de Ciências: fundamentos e métodos", em virtude de essa ser a obra base referencial da 
AT. A perspectiva da AT é apontada como um desafio de pensar o currículo e a programação das disciplinas, para o qual é necessária uma ruptura com a lógica atual que organiza os conteúdos com base em conceitos cientíicos,

Trata-se, então, de articular, na programação e no planejamento, temas e conceitos científicos, sendo os temas, e não os conceitos, o ponto de partida para a elaboração do programa, que deve garantir a inclusão da conceituação a que se quer chegar para a compreensão científica dos temas pelo aluno (DELIZOICOV; ANGOTI; PERNAMBUCO, 2007, p. 273).

Com base em teorias epistemológicas contemporâneas (Kuhn, Bachelard, Fleck), os autores reforçam a ideia já apresenta por Delizoicov (1991), referente à interação não neutra entre sujeito e objeto. Assume-se o pressuposto de um sujeito coletivo, constituído pelas esferas simbólica, social e produtiva. Ou seja, um sujeito em que à medida que interage, estabelecendo relações com o meio físico e social, se constitui um sujeito coletivo. Entende-se esse sujeito como ontológico e epistêmico. A qualidade das interações que esse sujeito (aluno) está tendo é fundamental nesse processo, por isso é imprescindível que o professor planeje e organize atividades de aprendizagem mediante interações adequadas, as quais possibilitem a apropriação dos conhecimentos escolares científicos (DELIZOICOV; ANGOTI; PERNAMBUCO, 2007).

Além disso, é importante, também, considerar os objetos como não neutros, pois esses possuem uma significação por estarem em determinados contextos de relações que podem mudar. Assim, em determinados contextos, os valores e as linguagens científicas não são os mesmos que os compartilhados pela comunidade científica. Uma situação é o conhecimento de senso comum de alunos que não têm as mesmas significações do corpo de conhecimento científico (DELIZOICOV; ANGOTTI; PERNAMBUCO, 2007).

Essas considerações têm implicações na atuação docente. O professor não deve considerar seu aluno como uma "tábula rasa". Ele é um sujeito cognoscitivo, que estabelece relações com seu meio, mais amplo que apenas o meio escolar e traz para a escola conhecimentos prévios. Além do mais, os conhecimentos trabalhados pelo professor são historicamente contextualizados, logo não podem ser entendidos como prontos, acabados e absolutamente verdadeiros (DELIZOICOV; ANGOTI; PERNAMBUCO, 2007). 
A epistemologia de Johannes Hessen e a gnosiologia de Paulo Freire

Os conhecimentos que balizam os conteúdos programáticos escolares são também selecionados por critérios não neutros. Delizoicov (1991) argumenta sobre a relevância de se haver critérios para estabelecer quais objetos e conhecimentos se tornarão conhecimentos escolares. $\bigcirc$ autor chama atenção para que não se faça uma interpretação equivocada de que o conhecimento universal se reduza aos conteúdos dados pelos livros didáticos e programas escolares já estabelecidos.

Delizoicov, Angotti e Pernambuco (2007) complementam suas análises com base em Freire e Snyders, pontuando que os temas a que esses autores se referem são o objeto de estudo a ser compreendido no processo educativo e, dessa forma, constituem-se como objetos de conhecimento. Os autores destacam como aspecto mais significativo o fato de que a estruturação das atividades educativas desses educadores rompe com o tradicional paradigma curricular concebido numa abordagem conceitual, pois a conceituação científica é subordinada às temáticas significativas.

O processo didático-pedagógico deve garantir a apreensão do significado e a interpretação dos temas por parte do aluno, para que os significados e as interpretações possam ser problematizadas. Na perspectiva dialógica 12 de Freire, os significados e interpretações que o professor é portador também precisam estar presentes. $\bigcirc$ diálogo refere-se aos conhecimentos de ambos. Em síntese,

A abordagem de conceitos científicos é ponto de chegada, quer da estruturação do conteúdo programático quer da aprendizagem dos alunos, ficando o ponto de partida com os temas e situações significativas que originam, de um lado, a seleção e organização do rol de conteúdos, ao serem articulados com a estrutura do conhecimento científico e, de outro, o início do processo dialógico e problematizador (DELIZOICOV; ANGOTTI; PERNAMBUCO, 2007, p. 194).

A dinâmica de estruturação de sala de aula é dada pelo processo de codificação-problematização-descodificação proposto por Freire. Tal processo deve ser planejado explorando-se tanto a dimensão dialógica do ato educativo, quanto a dimensão problematizadora do ato gnosiológico. Pretende-se a apreensão pelo educador dos significados que o aluno atribui às situações e a apreensão do aluno via problematização de uma intepretação oriunda de 
conhecimentos escolares científicos introduzidos pelo professor. Uma possibilidade de atuação docente em sala de aula para contemplar esses aspectos é a dinâmica dos Três Momentos Pedagógicos (DELIZOICOV; ANGOTTI; PERNAMBUCO, 2007).

processo de articulação entre temas e conceitos científicos é denominado por Freire como redução temática. Trata-se de um processo de delimitação da temática, em que cada especialista apresenta o projeto de "redução" de seu tema, buscando os núcleos fundamentais que dão a visão geral do tema "reduzido". Assim, definidos os temas que a escola irá trabalhar, os professores, em trabalho coletivo, selecionam os conhecimentos que irão compor o rol de conteúdos programáticos, para melhor compreensão do tema, os quais serão desenvolvidos com base na dimensão dialógica e problematizadora (DELIZOICOV; ANGOTI; PERNAMBUCO, 2007).

Os autores sugerem, ainda, a inclusão de alguns conceitos supradisciplinares na área das ciências naturais, chamados de conceitos unificadores (ANGOTII, 1993). Esses conceitos - os quais são transformações, regularidades, escalas e energia - são complementares aos temas, podendo constituírem-se como âncoras para a aquisição de saberes ou para minimizarem fragmentações do pensamento dos estudantes.

Relembrando a visão epistemológica de Hessen, tem-se que os elementos principais do ato de conhecer são: sujeito, objeto e imagem. $\bigcirc$ sujeito do conhecimento irá relacionar-se com o objeto do conhecimento, apreendendo-o por meio da imagem que o sujeito cria sobre o objeto. De forma esquemática (Figura 2), pode-se representar a visão de Hessen sobre o ato de conhecer como: 
Figura 2 - Visão epistemológica de Hessen sobre o ato de conhecer

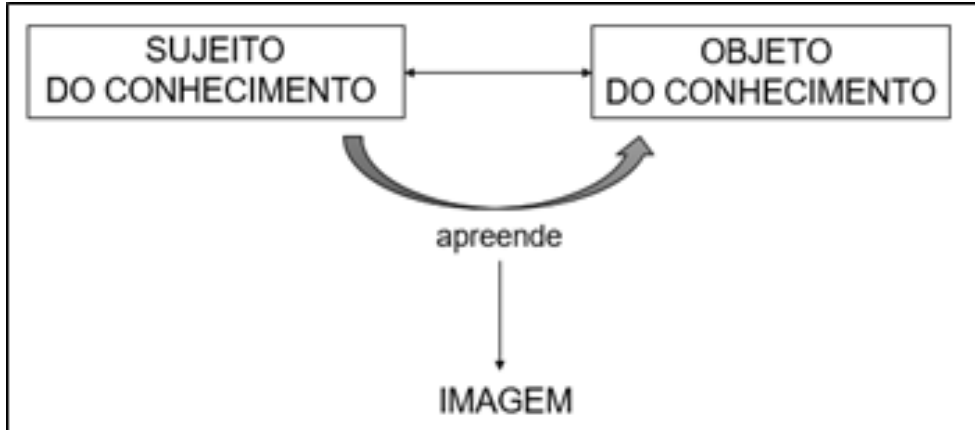

Fonte: Autores

Brick (2017), usando dessa ideia, analisa o ato educativo de modo geral e coloca como sujeitos do conhecimento o professor, o aluno e os cientistas e, como objeto, a matéria, ou seja, o conteúdo a ser trabalhado em sala de aula. Ao transcender essas análises para a perspectiva da AT, pode-se considerar os mesmos sujeitos envolvidos. Entretanto, o objeto de conhecimento passa a ser os temas, ao invés da matéria. Os temas são o ponto de partida e deles serão selecionados os conteúdos necessários para a sua apreensão. Assim, a representação com base nos elementos de Hessen para a AT pode ser representada (Figura 3).

Figura 3 - Elementos da epistemologia de Hessen para a perspectiva da AT

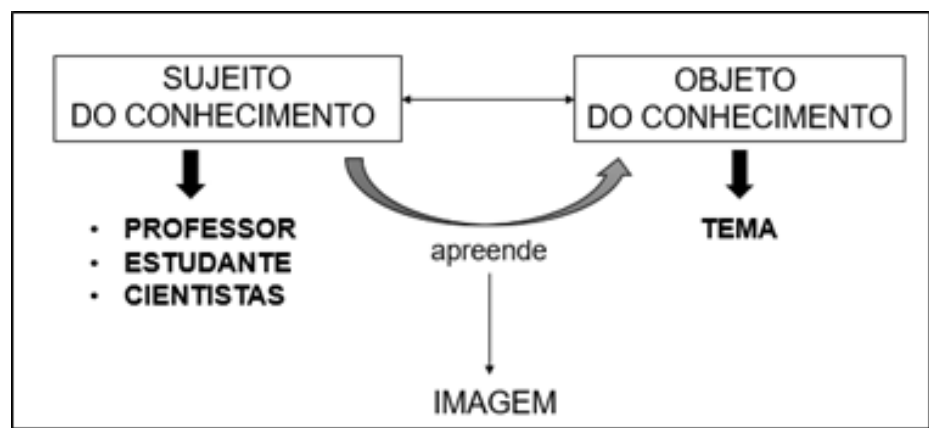

Fonte: Autores 
Aprofundando sua análise, Brick apresenta os elementos constituintes de uma situação gnosiológica de ensino. Pensando esses elementos em uma perspectiva da AT, propõe-se o seguinte esquema (Figura 4):

\section{Figura 4 - Elementos gnosiológicos da situação de ensino na perspectiva da AT}

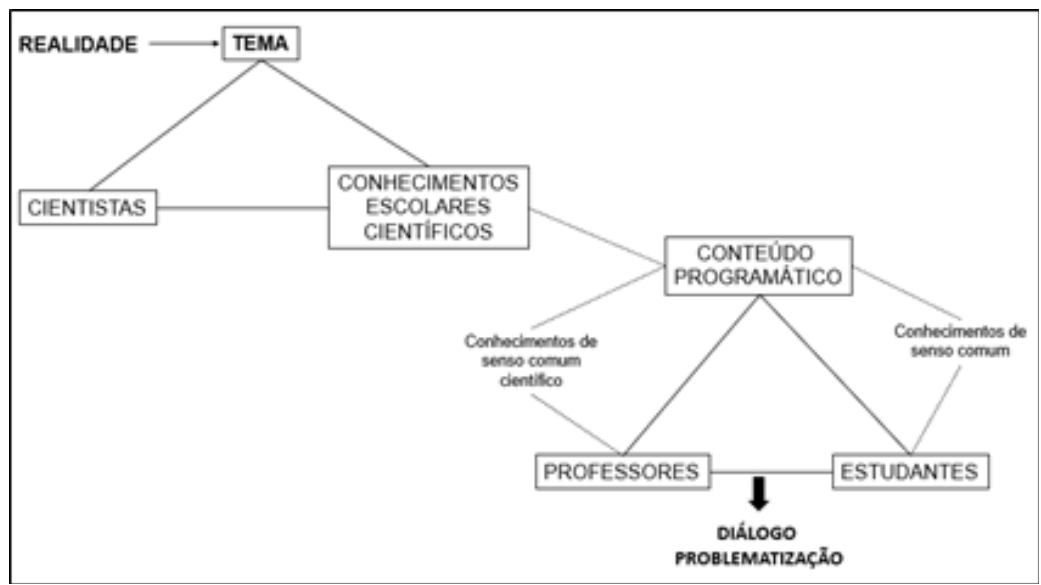

Fonte: Autores

Os temas, objeto de conhecimento, são o ponto de partida. Destaca-se, que tais temas devem partir da realidade dos estudantes, pois esses dialogam com e sobre os fenômenos e/ou situações em que vivem. Quando há o desenvolvimento de uma ATF, a qual passa por um processo de Investigação Temática (IT), os temas são naturalmente situações limites e contradições sociais da realidade dos estudantes. Entretanto, uma AT não necessariamente passa por um processo de IT, e os temas podem ser escolhidos pelos professores. Nesses casos, os temas possuem uma relação próxima da realidade, mesmo que não sejam provenientes de processos de investigação. É a partir dos temas que os professores selecionam os conhecimentos escolares científicos necessários para a sua apreensão. Tais conceitos estão relacionados com os cientistas produtores desses conhecimentos. É importante relembrar que essa relação não é neutra.

Selecionados os conceitos científicos, os professores determinam o conteúdo programático a ser desenvolvido e, através desses, os professores 
A epistemologia de Johannes Hessen e a gnosiologia de Paulo Freire

interagem com os estudantes. Optou-se por empregar a palavra professores no plural, para enfatizar que este trabalho deve ser coletivo e interdisciplinar. A interação entre os sujeitos cognoscentes professores e alunos sobre o objeto do conhecimento - tema - ocorre por meio de diálogo e problematização.

Destaca-se, ainda, o diálogo e a problematização no esquema para enfatizar a sua importância nesse processo de apreensão. $\bigcirc$ diálogo gera a comunicação, sem a qual não há verdadeira educação "[...] a que se instaura como situação gnosiológica, em que os sujeitos incidem seu ato cognoscente sobre o objeto cognoscível que os mediatiza" (FREIRE, 2018, p. 115). A problematização gera a dialogicidade. Sem a problematização não é possível a relação dialógica essencial para a cognoscibilidade dos sujeitos cognoscentes em torno do objeto cognoscível (FREIRE, 2018).

Indicam-se, também, no esquema, os conhecimentos de senso comum, tanto dos estudantes quanto dos professores, pois, no ato gnosiológico, não se pode deixar de considerá-los. Retomando o que Freire já pontuava, os estudantes não são tábulas rasas, e seus conhecimentos prévios devem ser problematizados pelos professores. Assim como, também, os professores possuem conhecimentos de senso comum, que estão igualmente envolvidos nesse 16 processo, nas palavras de Delizoicov,

[...] ao se associar o conhecimento vulgar ou conhecimento do senso comum a uma concepção de mundo do educando, está também deve sofrer mudanças com rupturas na medida em que se pretende desenvolver a conceituação e o pensamento científico durante o processo de aprendizagem (DELIZOICOV, 1991, p. 12).

Dessa forma, acredita-se que foi possível relacionar e discutir teoricamente os elementos envolvidos no processo de apreensão de temas da perspectiva da AT, com um viés epistemológico-gnosiológico apoiado, principalmente, no epistemólogo Hessen e no contexto educativo com Freire, Delizoicov e Brick.

\section{Considerações finais}

Por meio dessa construção teórica foi possível evidenciar, utilizando-se da visão epistemológica de Hessen, que o conhecimento, de forma geral, é 
caracterizado por três elementos principais: sujeito, imagem e objeto. Sujeito e objeto possuem características próprias (ontológicas) e a função do sujeito é apreender o objeto, assim como a função do objeto é ser apreensível. A imagem surge para o sujeito através da sua relação com objeto, pois ao apreender o objeto, o sujeito sai da sua esfera própria e apreende determinações da esfera do objeto, ou seja, é o meio com o qual a consciência cognoscente apreende seu objeto.

Para transcender esse entendimento para a situação da AT, utilizou-se, primeiramente, do estudo de Brick (2017), que, por meio da visão de Hessen, analisou práticas educativas, tendo como referência a realidade e caracterizou, de modo geral, uma situação de ensino através de uma interpretação gnosiológica. $\bigcirc$ autor considera que uma situação de ensino acontece entre professor, aluno e o "conteúdo" a ser aprendido. Logo, professor e aluno são sujeitos dos conhecimentos essenciais do ato educativo. Além deles, há, ainda, sujeitos históricos produtores de conhecimento reconhecido e legitimado, os cientistas, os quais participam da situação de ensino, visto que enquanto estiverem vinculados pelo professor, pelo aluno ou por ambos, o conhecimento por eles produzido. As relações são complementadas com o objeto do conhecimento, que será o "conteúdo" ou a "matéria", resultado do processo de transposição didática.

Por meio disso, passou-se a analisar a situação de ensino na perspectiva da AT. Pode-se considerar os mesmos sujeitos envolvidos. Entretanto, o objeto de conhecimento passou a ser o tema, ao invés da matéria. Os temas são os pontos de partida e deles serão selecionados os conteúdos necessários para a sua apreensão. Ampliando o olhar, com base na gnosiologia de Freire, entendeu-se que os temas, objeto de conhecimento, são os pontos de partida que devem advir de situações significativas da realidade dos estudantes, pois esses dialogam com e sobre os fenômenos e/ou situações em que vivem. É a partir dos temas que os professores selecionam os conhecimentos escolares científicos necessários para a sua apreensão. Selecionados os conceitos científicos, os professores determinam o conteúdo programático a ser desenvolvido e, através desses, interagem com os estudantes de forma interdisciplinar, dialógica e problematizadora.

Dessa maneira, este trabalho construiu relações teóricas para fundamentar o processo de apreensão dos temas na perspectiva curricular da AT, afinal, entender, epistemologicamente, como ocorre o processo de apreensão 
dos temas é importante para a estruturação das atividades didáticas. Ressalta-se, que a compreensão temática é mais ampla e mais complexa que uma compreensão apenas conceitual, pois envolve elementos sociais da realidade dos estudantes, com intuito de transformação. Espera-se, dessa forma, contribuir com o Ensino de Ciências, proporcionando embasamento teórico para práticas pedagógicas e pesquisas futuras.

\section{Referências}

ANGOTTI, José André Peres. Conceitos Unificadores e Ensino de Física. Revista Brasileira de Ensino de Física, v. 15, n. 1-4, p. 191-198, 1993.

BRICK, Elizandro Maurício. Realidade e ensino de ciências. 2017. 400f. Tese (Doutorado em Educação Científica e Tecnológica) - Programa de Pós-Graduação em Educação Científica e Tecnológica, Universidade Federal de Santa Catarina. Florianópolis, Santa Catarina, 2017.

DELIZOICOV, Demétrio; ANGOTTI, José André Peres; PERNAMBUCO, Marta Maria. Ensino de Ciências: fundamentos e métodos. 2 ed. São Paulo: Cortez, 2007.

DELIZOICOV, Demétrio. Conhecimento, tensões e transições. 1991. 21 ff. Tese (Doutorado em Educação) - Programa de Pós-Graduação em Educação, Universidade de São Paulo, São Paulo, 1991.

FREIRE, Paulo. Pedagogia do oprimido. 65. ed. Rio de Janeiro/ São Paulo: Paz e Terra. 2018.

HALMENSCHLAGER, Karine Raquiel. Abordagem de temas em ciências da natureza no ensino médio: implicações na prática e na formação docente. 2014. 373 p. Tese (Doutorado em Educação Científica e Tecnológica) - Programa de Pós-Graduação em Educação Científica e Tecnológica, Universidade Federal de Santa Catarina. Florianópolis, Santa Catarina, 2014.

HESSEN, Johannes. Teoria do conhecimento. 3. ed. São Paulo: Editora WMF Martins Fontes, 2012.

SANGIOGO, Fábio André. A elaboração conceitual sobre representações de partículas submicroscópicas em aulas de química da educação básica: aspectos pedagógicos e epistemológicos. 2014. 219 p. Tese (Doutorado em Educação Científica e Tecnológica) Programa de Pós-Graduação em Educação Científica e Tecnológica, Universidade Federal de Santa Catarina, Florianópolis, 2014. 
SAUL, Ana Maria; SAUL, Alexandre. Uma trama conceitual centrada no currículo inspirada na pedagogia de Paulo Freire. Revista e-Curriculum, v. 16, n. 4, p. $1142-1174,2018$.

SOUZA, Kátia Reis de; MENDONÇA, André Luís de Oliveira. A atualidade da 'pedagogia do oprimido' nos seus 50 anos: a pedagogia da revolução de Paulo Freire. Trabalho,

Educação, Saúde, Rio de Janeiro, v. 17, n. 1, p. 1-12. 2018.

Dra. Sabrina Gabriela Klein

Universidade Federal de Santa Maria (Brasil)

Doutorado em Educação em Ciências

EMEF Marcílio Dias; EMEF Professor Políbio do Valle; EMEF Rufino Leal

Grupo de pesquisa: GEPECiD

Orcid id: https: / / orcid.org/0000-000 1-5944-0754

E-mail: sabrinaklein92@gmail.com

Profa. Dra. Cristiane Muenchen

Universidade Federal de Santa Maria (Brasil)

Doutorado em Educação Científica e Tecnológica

Docente no Programa de Pós-Graduação em Educação em Ciências: Química da

Vida e Saúde

Grupo de pesquisa: GEPECiD

Orcid id: https:/ / orcid.org/0000-0003-3 $144-0933$

E-mail: crismuenchen@yahoo.com.br

Recebido 27 abr. 2021

Aceito 26 jul. 2021 